\section{Nadia Rasool*}

Sneha Mariam

Lal

\section{S Vidhyadhara} Shetty
PG Scholar, Department of Conservative Dentistry and Endodontics, Yenepoya Dental College, Manglore. *Corresponding Author

PG Scholar, Department of Conservative Dentistry and Endodontics, Yenepoya Dental College, Manglore.

Professor, Department of Conservative Dentistry and Endodontics, Yenepoya Dental College, Manglore.

The aim of this study was to determine different causes of endodontic treatment failure in patients who approached our Department of Conservative Dentistry and Endodontics for re- treatment. This study included one hundred fifty patients of both genders with different post endodontic treatment complaints. Clinical and radio- graphic examination was used to confirm treatment failure. The most common clinical symptoms were tenderness, tenderness and pain, or swelling (72\%, 29.3\% and $22.7 \%$ respectively). The common causes of endodontic treatment failure were poorly filled (40\%), under filled (34.7\%) and no root canal filling (17.3\%). Root canal failure due to overfilling was 5.3\%. Most of these failed cases were either treated by internees (House officers) in the teaching institutes $(34.7 \%)$ or general dental practitioners $(57.3 \%)$.

\section{INTRODUCTION}

Preoperative causes that influence RCT outcome include misdiagnosis, errors in treatment planning, poor case selection, or treatment of a tooth with a poor prognosis. [1] Often, radiographic interpretation or lack of proper radiographs can interfere with the operator's ability to predict the outcome, resulting in poor operative execution. Sjogren et al. indicated that one of the most important factors influencing the prognosis of endodontic treatment is the preoperative status of the tooth. He furthermore referenced studies demonstrating that the success rate in endodontic therapy is significantly influenced by the presence or absence of a pretherapeutic radiographic lesion. Teeth with an apical radiolucency may show up to a $20 \%$ lower success rate than teeth without such lesions. Regardless of how the tooth presents, proper interpretation and subsequent treatment planning prior to initiating RCT will allow for better care and outcome. [2] It is generally accepted that outcome of endodontic treatment is positively correlated with the technical quality of root canal sealing which is supposed to provide a hermetic seal against bacterial ingress. [3] Studies have shown that unprepared areas of the root canal system may harbor bacteria and necrotic tissue that may result in root canal treatment failure. [4] Thus the primary goal of root canal treatment should be to eliminate completely or reduce the microbial population with in the root canal system and to prevent reinfection by providing tight seal. The most common causes of endodontic treatment failure are insufficient cleaning and inadequate sealing of the root canal system. [5]

Criteria used to assess quality of root fillings often are based on the radiographically assessed characteristics of density (the extent to which the root filling material uniformly and completely fills the canals) and extension (the distance from the end of the root filling material to the radiographic apex). Root filling considered as inadequate by these criteria do not necessarily fail, nor do root fillings designated as adequate by these criteria results in satisfactory endodontic results. However, many clinical studies on root canal fillings suggest that poor root canal filling density and extension are associated with postoperative apical periodontitis. $[6,7,8]$ Voids in the root fillings represent spaces where residual microflora inhabit and subsequently trans-port endotoxins to the root apex, stimulating an inflammatory response.[9] In cases of under-obturation, if spaces left behind are free of microorganisms, under- obturation is unlikely to increase the risk of periapical inflammation. Root canal failure may also occur due to some other reasons such as missed canal, vertical root fracture, procedural errors, and separated instrument. Procedural errors and separated instrument will ultimately result in under filled root canals. No study on the causes of failure of root canal treatment was done in our institution before. The aim of this study was to see the most common causes of root canal failure among the patients, reported to the Department of Conservative Dentistry and Endodontics for retreatment.

\section{METHODOLOGY}

Subjects included in the study were one hundred fifty patients who reported for retreatment of endodontically treated teeth. The teeth with tenderness to pressure, pain, swelling, and active sinus tract were declared as an endodontic failure cases. This was a descriptive study and the duration of the study was six months. The subjects were selected on convenience sampling method. The sample size was not predetermined, however cases of endodontic treatment failure recorded during predetermined period of six months was the sample size. Information's regarding the failed cases was collected on a questionnaire prepared in our Department. Informed consent was taken from the subjects and the institutional ethical committee approved the study. The teeth and the surrounding tissues were examined for the presence of tenderness, swelling, fracture of crown of tooth or sinus tract. Teeth with vertical root fracture, split crown, periodontal diseases were excluded. The quality of coronal restoration was also observed. A well-developed radiograph was taken for each case and was thoroughly read under illumination with the help of magnifying mirror by the principal author, to determine the cause of failure by observing the status of root canal filling or any other abnormality in the root canal system. The root filling more than $2 \mathrm{~mm}$ short of the radiographic apex were considered under filled while filling that ends beyond the radiographical apex were considered overfilled. Any voids or radiolucent space running along the entire or some of the working length of root filling were considered poorly filled. Any undesirable deviation from natural canal path was considered ledge. Perforation and separated instrument were also looked for. The subjects were then scheduled for re-root canal treatment. Fig 1: Gender Distribution

\section{RESULTS}

Among 150 subjects included in the study, $57.3 \%$ were male and $42.7 \%$ were females with mean age 31 years (max. 62 and $\min .12$ years). 
Sixty percent $(60 \%)$ of the failed teeth were treated at teaching institutes followed by private clinics $34.7 \%$. A negligible number of subjects $(2.7 \%)$ were those who were treated at periphery hospital or unqualified persons (Table 1).

Table 1 Distribution Of Failed RCT According To The PracticeWork

\begin{tabular}{|l|l|l|}
\hline & Frequency & Percentages \\
\hline Teaching institute & 90 & $60 \%$ \\
\hline Periphery Hospital & 4 & $2.7 \%$ \\
\hline Unqualified & 52 & $34.7 \%$ \\
\hline Private clinic & 4 & $2.7 \%$ \\
\hline Total & 150 & $100 \%$ \\
\hline
\end{tabular}

Graph1 Distribution of failed RCT according to the practice work

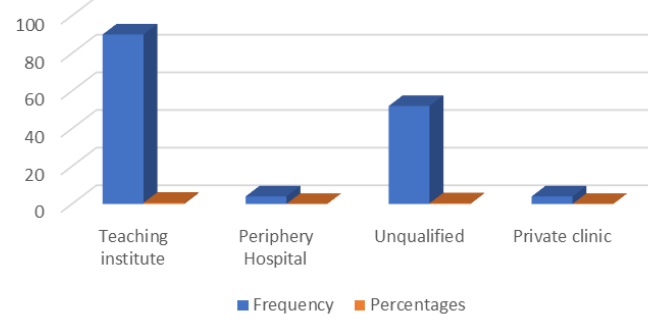

Out of one hundred fifty failed cases $57.3 \%$ were treated by general dental practitioners (GDPs) and $34.7 \%$ by internees (Table 2).

Table 2 Distribution Of Failed RCT According To The Practitioner

\begin{tabular}{|l|l|l|}
\hline & Frequency & Percentages \\
\hline G.D.P & 86 & $57.3 \%$ \\
\hline Specialist & 4 & $2.7 \%$ \\
\hline Unqualified & 8 & $5.3 \%$ \\
\hline Student & 52 & $34.7 \%$ \\
\hline Total & 150 & $100 \%$ \\
\hline
\end{tabular}

Graph 2 Distribution of failed RCT according to the practitioner

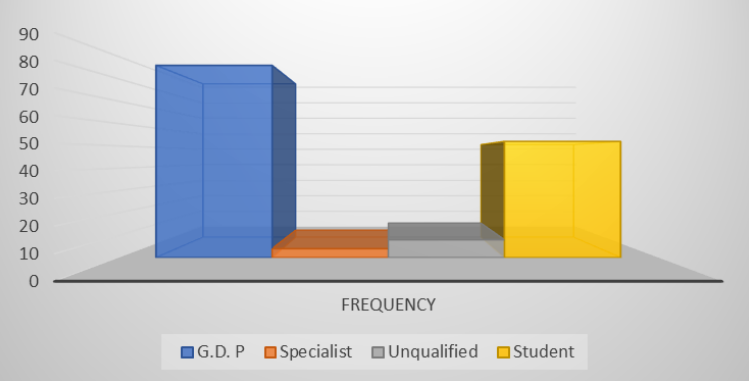

The subjects presented with various complaints and the most common complaint (72\%) was tenderness to percussion (Table 3). In some of the cases both pain and tenderness were present. In $86.7 \%$ of cases an obvious radiolucency was present at the apex of failed teeth

Table 3 Post Endodontic Treatment Complications

\begin{tabular}{|l|l|l|}
\hline Complications & Frequency & Percentages \\
\hline Tenderness & 108 & $72 \%$ \\
\hline Pain & 44 & $29.3 \%$ \\
\hline Swelling & 34 & $22.7 \%$ \\
\hline Mobility & 2 & $1.3 \%$ \\
\hline Sinus Tract & 8 & $10.7 \%$ \\
\hline Loss of restoration & 22 & $14.7 \%$ \\
\hline Split tooth & 2 & $1.3 \%$ \\
\hline Fractured crown & 6 & $4 \%$ \\
\hline
\end{tabular}

|www.worldwidejournals.com|

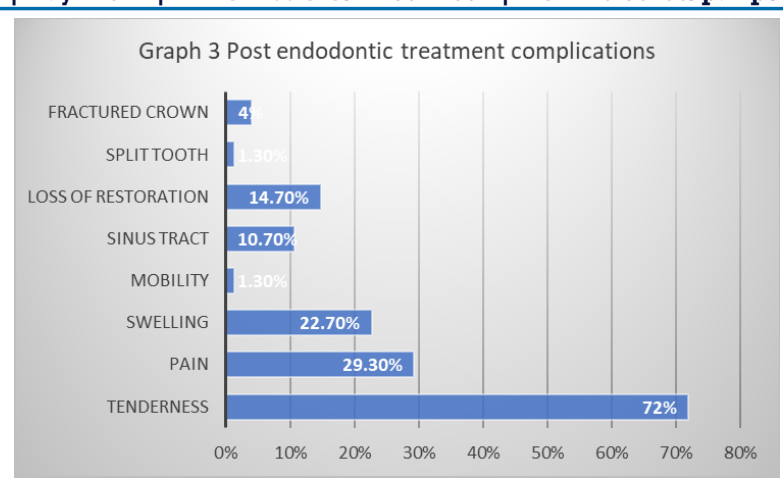

In $14.7 \%$ cases the coronal restoration was lost while in three cases a part of crown of the tooth was fractured. Twelve percent (09 subjects) were having metal ceramic crown on their root canal treated teeth. The most common defects found in the root canal filling were either poor root canal filling, under filling or no root canal filling $(40 \%, 34.7 \%$ and $17.3 \%$ respectively. Failure due to over filling was 5.3 (Table 4).

\section{Table 4 Radiographic Interpretations}

\begin{tabular}{|l|l|l|}
\hline Defects & Frequency & Percentages \\
\hline Poorly filled & 60 & $40 \%$ \\
\hline Under filled & 52 & $34.7 \%$ \\
\hline Over filled & 8 & $5.3 \%$ \\
\hline Not filled & 26 & $17.3 \%$ \\
\hline Fracture instrument & 2 & $1.3 \%$ \\
\hline Perforation & 2 & $1.3 \%$ \\
\hline Total & 150 & $100 \%$ \\
\hline
\end{tabular}

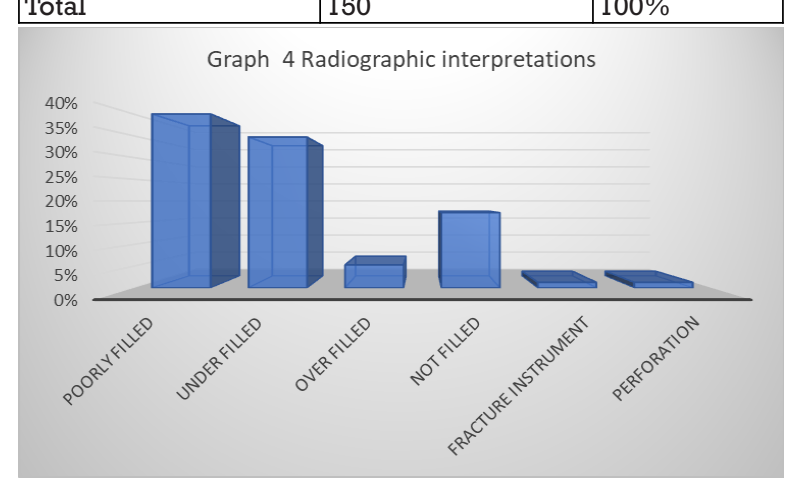

In 92 cases $(61.3 \%)$ failure occurred within six months of the treatment while 34 cases $(22.7 \%)$ survived up to one year. Only 24 cases ( $16 \%$ ) remained symptomless for more than a year.

\section{DISCUSSION}

A successful outcome for root canal treatment relies on adequate removal of microorganisms form the root canal system and prevention of recolonization or propagation of residual micro-organisms through the placement of well extended homogenously dense root filling and adequate coronal restoration. [10] In the present study the most common causes of root canal treatment failure observed were either poor, under, or no root canal filling. This is in agreement with many other studies, which show that quality of root canal filling influence the prognosis of endodontic therapy. $[11,12,13]$ Inadequate preparation and filling of the root canal system mean that residual spaces and microorganisms are left behind which ultimately result in endodontic treatment failure. According to Cohen and Burns, $1 \mathrm{~mm}$ of the canal with the diameter of $0.25 \mathrm{~mm}$ can harbor nearly 80,000 Streptococci. [14] Literature shows that $1 \mathrm{~mm}$ loss in working length increased the chances of endodontic treatment failure by $14 \%$ in teeth with apical periodontitis. [15] The failure, in the present study, was determined by radiographic quality of the root canal filling. The teeth included in this study were filled by cold lateral condensation technique. This technique in conjunction with a root canal sealer is most widely 
accepted technique for root canal filling. [16] It is simple and versatile technique. However, there is lacking of extensive preclinical endodontic practice at undergraduate level in the region where this study was conducted which results in inadequate endodontic treatment. Barrieshi et al have reported that technical quality of root canal treatment performed by student was adequate in less than 50\%. [17] Although it is agreed that radiographic technical quality of root canal filling influences the success outcome, there are other factors that may play role in the endodontic failure such as debridement and reduction in the population of microorganisms, adequacy of coronal restorations. [18] Due to the limitation of the present study, these factors cannot be assessed but they are definitely contributing to the success and failure of endodontic treatment. The present study shows that most of the endodontic failure occurred in molars (Upper/Lower) and maxillary premolars. This may be due to the complex nature and numerous anatomical variations in the root canal system of these teeth. Curved, tight canals and presence of additional canals makes these teeth difficult to be treated successfully by internees or GDPs. In the present study, general dental practitioners treated $57.3 \%$ of the failed cases. Among this $34.7 \%$ were treated in private clinics. LupiPegurier et al (2002), in a study of adequacy of root canal treatment in French population have found low values of adequate root canal filling in general practice. [19] Hayes et al (2001) believe that more specialist endodontist are needed to improve the treatment standard. Dugas et al (2003), however, have found no significant improvement in clinical success rate through specialist training and recommend that greater number of subjects must be included in the study to validate the results.[20]

Teeth of complex nature definitely need referral to the endodontist or to the dentist who have taken intensive training in endodontics. The present study also shows that periapical radiolucency was present in $86.7 \%$ cases. Since the patients were treated for root canal at different places and no previous radiographs or other record was available, therefore it is the limitation of the present study to comment on either the presence of perapical radiolucencies before or its occurrence after root canal treatment and also the possible role of these periapical radiolucencies on the endodontic treatment failure. Yan Zhong et al (2008), however, have seen a greater influence of apical radiolucecy on the prognosis of root canal treatment. [21] Teeth with apical radiolucency presumably already have bacteria present in the apical region compared to the teeth without apical radiolucency which might or might not have bacteria present at the apical region. Peak et al (2001) however, have reported a better endodontic treatment outcome in teeth with periapical radiolucencies $(87 \%)$ than without (80\%). [22] Endodontic treatment failure due to separated instrument and perforation was $1.3 \%$ respectively. In two cases, treated by skilled person, although the root canal filling was adequate, failure occurred. In endodontically well treated teeth, failure occurs due to the presence of resistant strains of microorganisms in the periapical area. Literature has shown that endodontic treatment failures are frequently associated with grampositive aerobic and facultative microorganisms. [23] Failure due to the presence of Enterococcus faecalis in adequately treated teeth is well reported. $[24,25]$

\section{CONCLUSIONS}

It was concluded from the present study that endodontic treatment failure occurs in poorly filled, under filled or missed root canal. Molars, both upper and lower and upper premolars have high failure rate than anterior teeth. Moreover, the endodontic treatment done by both GDPs and internees was not up to the standard.

\section{REFERENCES}

[1]. Walton RE, Torabinejad M. Principles and practice of endodontics. 2nd Edition.WB Saunders Company. 1996;324-334.

[2]. Sjogren U, Hagglund B, Sundqvist G, Wing K. Factors affecting the long-term results of endodontic treatment. Journal of Endodontics. Oct. 1990;16(10).

[3]. Sjogren U, Hagglund B, Sundqvist G, Wing K. Factors affect- ing the long-term results of endodontic treatment.J Endod 1990; 16:498-504.

[4]. Siqueria JF, Araujo MCP, Garua PF, Fraga RC, SabotaDantas CJ. Histological evaluation of the effectiveness of five instru- mentation techniques for cleaning the apical third root canals.J Endod 1997;23:499-502.

[5]. Siqueria JF. Etiology of root canal treatment failure. Why well treated teeth can fail.IntEndodJ 2001;34:1-11.

[6]. Kirkevang LL, Orstavik D, Horsted-Bindslev P, Wenzel A. 22 Periapical status and quality of root fillings and coronal restorations in a Danish population. IntEndod J2000;33:509-15.

[7]. Tronstad L, Asbjornsen K, Doving L, Pedersen I., Eriksen HM. 23 Influence of coronal restorations on the periapical health ofSiqueira JF jr.Aetiology of root canal treatment failure: why well treated teeth can fail. IntEndod J 2001;34: 110.

[8]. Hommez GM, Coppens CR, De Moor RJ. Periapical health related to the quality of coronal restorations and root fillings. IntEndod J 2002;35:680-89.

[9]. Ray HA, Trope M. Periapical status of endodontically treated teeth in relation to the technical quality of the root filling and the coronal restoration. IntEndod L 1995; $28: 12-18$.

[10]. Soikkonen KT. Endodontically treated teeth and periapical findings in the elderly. IntEndod J 1995;28:200-203.

[11]. Noor N, Maxsood A, Kaleem K. Cross sectional analysis of endodontic failure in PIMS. Pakistan Oral \& Dent Jr 2008; 28:99-102.

[12]. Nie Q, Lin J. Comparison of intermaxillary tooth size discrep- ancies among different malocclusion group. Am J OrthodDentofacialOrthop 1999; $116: 539-$ 44.

[13]. Alkofide E, Hashim H. Intermaxillary tooth size discrepancies among different malocclusion classes: a comparative study.J ClinPediatr Dent. 2002; 26:4383-87.

[14]. Cohen S, Burns RC. Pathways of Pulp 6thed. St Louis Mosby; 1994

[15]. Chugal NM, Clive JM, Spangberg LS,. Endodontic infection: some biologic and treatment factors associated with outcome. Oral Surg Oral Med Oral Pathol Oral RadiolEndod 2003;96:81-90.

[16]. Qualtrough AJE, Dummer PMH. Undergraduate endodontic teaching in the United Kingdom: an update. IntEndodJ 1997;30:234-40.

[17]. Lufkin AH, Brown DC, Buchanan LS. A reconstructed versus traditional instruments in canals shaped by novice operator.IntEndodJ 2001;34:476-84.

[18]. Eriksen HM, Kirkevang LL, Petersen K. Endodontic epidemi- ology and treatment outcome general considerations. Endo- dontic Topics 2002;2: 7-9.

[19]. Lupi-Pegurier L, Bertrand MF, Mullarbolla M, Rocca JP, Bolla M. Periapical status, prevalence and quality of endodontic treatment in an adult French population.IntEndodJ 2002;35:690-97.

[20]. Dugas NN, Lawrence HP, Teplitsky PE, Pharoah MJ, Fried- man S. Periapical health and treatment quality assessment of root filled teeth in two Canadian population. IntEndod J 2003;36: 181-92.

[21]. Zhong Y, Chasen J, Yamanaka R, Garcia R, Kaye KE, Kaufman SJ, Cai J, Wilcosky T, Trope M, Caplan JD. Exten- sion and density of root fillings and post operative apical radiolucencies in the Vetrans Affairs dental longitudinal study.J Endod 2008;34:798-803.

[22]. Periapical status and quality of root fillings and coronal restorations in a Danish population. IntEndod J2000;33:509-15.140-44.

[23]. Siqueira JF jr.Aetiology of root canal treatment failure: why well treated teeth can fail. IntEndod J 2001;34:1-10.

[24]. Sundqvist G, Figdor D, Persson S, Sjogren U. Microbiologic analysis of teeth with failed endodontic treatment and the outcome of conservative re treatment. Oral Surg Oral Med Oral Pathol 1998;85:86-93.

[25]. Hancock HH 3rd, Sigurdsson A, Trope M, Moiseiwitsch J. Bacteria isolated after unsuccessful endodontic treatement in a North American population. Oral Surg Oral Med Oral Pathol 2001;91:579-86. 